\title{
ALBERA, Dionigi; EADE, John (Ed.). New pathways in pilgrimage studies: global perspectives. New York: Routledge, 2016. $228 \mathrm{p}$.
}

Rodrigo Toniol ${ }^{*}$

*Universidade Estadual de Campinas - Campinas, SP, Brasil rodrigo.toniol@gmail.com 
Peregrinação é uma categoria cujas referências originais remontam ao cristianismo medieval. A despeito desse vínculo explícito, no entanto, o termo é empregado para descrever um amplo conjunto de deslocamentos com características próprias e destinos variados. Considerando apenas a literatura mais recente das ciências sociais, podemos encontrar estudos que mobilizam a categoria para descrever eventos presumidamente religiosos, como a visita de monges às montanhas sagradas do Tibete (Huber, 1999) ou viagens de sufistas a templos no Oriente Médio (Werbner, 2004), assim como o termo também pode ser utilizado para designar práticas seculares, como caminhadas em parques nacionais (Ross-Bryant, 2013) ou visitas a campos de concentração (Miles, 2002). Diante da variedade dos fenômenos empíricos descritos na chave da peregrinação, não é exagero desconfiar da pertinência analítica do uso do termo. Ou ainda, numa versão mais explícita dos limites aparentes dessa categoria, caberia perguntar: teríamos deixado de avançar com a crítica pós-colonial sobre o uso da noção de peregrinação, reificando, assim, sua pretensa universalidade apesar de sua genealogia cristã?

Em certa medida essa é a questão que anima os nove capítulos do livro New pathways in pilgrimage studies, organizado por Dionigi Albera e John Eade, publicado em 2017. Na obra, os autores não recusam o uso do termo peregrinação, como fica evidente pelo próprio título, mas optam por pluralizá-lo. Para isso, Albera e Eade organizaram o livro a partir de uma exigência dupla: que os capítulos descrevessem situações empíricas localizadas fora do eixo Estados Unidos-Europa e, ao mesmo tempo, que essas situações servissem como mote para que os autores apresentassem a tradição teórica local dos estudos sobre peregrinação. Resulta disso um livro sobre peregrinações na China, Índia, Sul asiático, Malásia, Oriente Médio, Ilhas do Pacífico, África subsaariana, México e Brasil, que também introduz seus leitores nas perspectivas e nos debates que constituíram a tradição das pesquisas sobre o tema em cada um desses contextos.

A originalidade da proposta do livro é também seu maior risco, já que apresentar tradições teóricas a partir de circunscrições nacionais pode terminar por paroquializar perspectivas, estabelecendo-as a partir de um contraste latente com as grandes teorias, estas, por sua vez, não apresentadas a partir de um território. Albera e Eade estão conscientes desse risco, mas explicitamente optam por assumi-lo considerando que apresentar tradições teóricas não anglófonas sobre o tema pode, a um só tempo, torná-las acessíveis ao público anglófono 
e também ter o efeito de situar as grandes teorias em função da localização de outros marcos teóricos. Bem-sucedido ou não em seu intento, o livro já surge como um marco para os estudos de peregrinação, propondo soluções originais para dilemas que, pelo menos, há duas décadas atravessam esse campo de discussão.

O capítulo de abertura do livro, "Pilgrimage in China", de Marcus Bingenheimer, está articulado por uma discussão tão elementar quanto potente para o debate sobre os limites dessa categoria fora do Ocidente cristão: como se traduz peregrinação? O tema é retomado noutros capítulos, mas o caso chinês talvez seja o mais emblemático justamente porque a variedade de traduções possíveis demonstram que não estamos diante de um problema de ordem nominalista, mas sim epistemológico, já que indica os limites de uma categoria universalizante diante de situações nuançadas na língua local.

Naquele país, os termos equivalentes mais próximos ao substantivo em inglês são chaoshan, que literalmente significa "ter um encontro com uma montanha", e jinxiang, que pode ser traduzido como "oferecer incenso". Jinxiang, no entanto, é especialmente utilizado em referência a um tipo específico de "peregrinações", aquelas em que alguma imagem é transladada entre templos, realizando um percurso predefinido. Já o primeiro termo, chaoshan, principalmente utilizado em sua forma variante chaosheng, que literalmente significa "ter um encontro com o sagrado", é empregado para descrever outra forma particular de "peregrinações": aquelas feitas em terras estrangeiras, isso é, fora da China. Entre as peregrinações estrangeiras, chaosheng, algumas possuem um termo próprio, como é o caso de: chaojin, reservado para remeter ao hajj, a viagem dos muçulmanos à Meca; qiufa, empregado para descrever as viagens de monges chineses para Índia; ou ainda, canxue, que é categoria utilizada para descrever o deslocamento de monges que viajam entre diferentes monastérios durante seu processo de formação. Para Bingenheimer, as variações nas formas de traduzir o termo na China ganham ainda mais relevância se contrastarmos suas características com a tradução mais usual para peregrinação no Japão, junrei, que significa "circulação e adoração no caminho". Após uma detalhada reconstrução linguística dessa categoria, o autor argumenta que, enquanto os termos chineses enfatizam o destino e os grupos religiosos que realizam o deslocamento, as variações japonesas da categoria dão centralidade à rota, ao itinerário, ao ato de deslocar-se de um ponto a outro. 
Também recorrendo a dimensões linguísticas das traduções do termo peregrinação, nesse caso para o híndi, Mathieu Claveyrolas é ainda mais enfático na crítica pós-colonial à categoria. Para isso, Claveyrolas traça a trajetória dos estudos sobre peregrinação na Índia apontando para o tenso diálogo dos pesquisadores locais com os paradigmas advindos da Europa e dos Estados Unidos. O modelo turneriano de análise ritual, por exemplo, afirma Claveyrolas, pouco repercutiu entre os teóricos indianos porque o foco de interesse desses pesquisadores estava relacionado com os eventos ocorridos em locais específicos e não no processo ritual mais amplo, como propunha o modelo de análise do antropólogo britânico. A esse interesse associa-se o que Claveyrolas reconhece como uma das principais marcas da tradição de pesquisas sobre peregrinações no contexto indiano, a análise desse fenômeno a partir de suas funções territoriais, destacando sua relevância para os movimentos políticos nacionalistas e também para a produção de identidades regionais.

O capítulo de Machel Boivin, "Sufism, pilgimage and saint worship", tematiza os debates sobre peregrinações feitos no contexto do sul da Ásia, uma das principais regiões islâmicas do mundo. Naquele contexto, significativamente marcado pela ortodoxia religiosa, a única forma de peregrinação reconhecida é o hajj. Para as pesquisas dedicadas ao tema, tanto as locais quanto as realizadas por estrangeiros, afirma Boivin, a consequência foi que outras formas de deslocamentos entre lugares religiosos foram invisibilizadas. Esse é o caso do ziyarat, uma importante prática de visitação de túmulos entre os muçulmanos, que apenas residualmente foi contemplada nos estudos de peregrinação. A discussão que Bovin realiza sobre o contexto muçulmano é curiosamente potente para ser desdobrada em análises sobre "peregrinações seculares", quando os deslocamentos e as visitações não integram roteiros institucionalmente estabelecidos e, muitas vezes, oscilam entre o não institucional e o proibido.

De maneira semelhante ao movimento realizado por Bovin, e igualmente relativo a um contexto muçulmano, Katia Boissevain, no capítulo "Studing religious mobility. Pilgrimage, shrine visits and religious tourism from the Maghreb to the Middle East", explora os variados motivos e formas de circulação entre Magrebe e o Oriente Médio. Além dos grupos de muçulmanos que se deslocam para ziyarat, há ainda uma onda crescente do chamado "turismo de Nova Era", realizado principalmente por ocidentais, majoritariamente estadunidenses e europeus, que se deslocam em grupo em direção a pontos 
energéticos ou espaços rituais distribuídos naquela região. A análise de Boissevain, a partir do diálogo com referências de estudos locais, investe em tratar das sobreposições que ocorrem entre os grupos, de muçulmanos e de new agers, que realizam essas peregrinações. Também são as sobreposições que Anna-Karina Hermkens enfatiza em seu texto sobre peregrinações na Oceania. Naquela região, afirma a autora, os estudos sobre peregrinação não se desenvolveram em torno de um grupo religioso específico, mas sim a partir de rotas e destinos de peregrinações. Algumas dessas rotas sequer constituem um território sagrado reconhecido por instituições religiosas, sendo, pelo contrário, espaços seculares, devotados à memória da nação, como por exemplo: campos de batalha, cemitérios e memoriais de guerra. Outras, ainda, são rotas tradicionais de grupos aborígenes, posteriormente também apropriadas por turistas da Nova Era.

Um dos efeitos valiosos da leitura do livro de Dionigi Albera e John Eade é perceber os vínculos entre as experiências locais de formas de peregrinação e os "estilos de análise" que delas emergiram. Assim, em contraste com os casos das regiões muçulmanas, em que as definições estritas do que seja peregrinação produziram tradições teóricas igualmente marcadas por esses limites, observamos situações como a australiana, em que a amplitude da noção de peregrinação permitiu que variados tipos de circulação e de espaços de visitação fossem inscritos nessa tradição de pesquisas. Nesse espectro, não deixa de ser instigante o caso narrado por Shirley du Plooy, sobre peregrinações na África meridional. O principal problema enunciado pela autora em seu texto não é o de como a tradição local de pesquisas sobre peregrinações foi forjada, mas sim as razões pelas as quais essas pesquisas se desenvolveram tão pouco na região. Entre outras hipóteses para tal fenômeno, está o traço colonial das ciências sociais constituídas na região, o que impelia pesquisadores, orientados por um modelo eurocêntrico de análise ritual, a buscarem peregrinações que ocorressem a partir das comunidades das populações nativas em direção a templos religiosos - busca, segundo Shirley du Plooy, sem sucesso, já que esse era um modelo de deslocamento pouco frequente naquele contexto.

Os estudos sobre cristianismo estão concentrados nos dois capítulos dedicados à América Latina, um dedicado ao Brasil e outro ao México. Em "Studies of catholicism and pilgrimage in Brazil", Carlos Alberto Steil apresenta um amplo panorama dos estudos sobre peregrinação realizados no país, desde o início da segunda metade do século XX até a primeira década dos anos 2000. 
Steil demonstra as conexões entre os processos históricos da Igreja Católica no país e os tipos de análise dedicadas às peregrinações na tradição das ciências sociais nacional. Ao realizar esse movimento, o autor introduz um novo conjunto de questões ao livro que dizem respeito às transformações das formas de presença das instituições religiosas e suas consequências para os "modos de peregrinar". Alejandra Aguilar Ros realiza um movimento semelhante em seu texto "Transcending symbols", delineando a trajetória do desenvolvimento das pesquisas sobre peregrinação no México, a partir da atenção de seus pesquisadores na tensão entre as práticas do catolicismo popular e os eventos controlados e organizados pela Igreja.

Apresentados aqui quase em forma de vinhetas, os capítulos de New pathways in pilgrimage studies são, em si, textos referenciais para aqueles que têm interesse pela área. Sua leitura permite ampliar o repertório de perspectivas metodológicas e enquadramentos analíticos possíveis nos campo dos estudos de peregrinação. Quando lidos em sequência, os artigos produzem ainda outro efeito, o de descentrar o próprio debate sobre os limites do termo peregrinação, enquanto categoria de análise. Assim, por mais recente que seja sua publicação, o livro organizado por Dionigi Albera e John Eade já se apresenta como uma referência incontornável na área e, de maneira mais ampla, oferece novos caminhos também para o avanço da crítica pós-colonial no campo dos estudos de religião.

\section{Referências}

HUBER, T. The cult of Pure Crystal Mountain: popular pilgrimage and visionary landscape in southeast Tibet. New York: Oxford University Press, 1999.

MILES, W. Auschwitz: museum interpretation and darker tourism. Annals of Tourism Research, v. 29, n. 4, p. 1175-1178, 2002.

ROSS-BRYANT, L. Pilgrimage to the national parks: religion and nature in the United States. New York: Routledge, 2013.

WERBNER, P. Pilgrims of love: the anthropology of a global Sufi cult. Bloomington: Indiana University Press, 2004. 